\title{
ARTICLE OPEN Rapidly increasing ethanol concentrations in rainwater and air
}

\author{
Joan D. Willey ${ }^{1}$, G. Brooks Avery ${ }^{1}$, J. David Felix ${ }^{2}$, Robert J. Kieber ${ }^{1}$, Ralph N. Mead ${ }^{1}$ and Megumi S. Shimizu ${ }^{1}$
}

Rainwater and gas phase ethanol concentrations increased approximately fourfold between 2010 and 2017 in Wilmington, NC, USA. This 8-year study demonstrates that the gas phase and rainwater concentrations of ethanol have risen due to increased production and use of ethanol as a biofuel. Rainwater ethanol concentrations are close to equilibrium with local atmospheric gas phase concentrations and have increased in proportion to increased air concentrations. Ethanol emissions are important because they impact the oxidizing capacity of the atmosphere due to the reactivity of the alcohol towards hydroxyl radical. Gas phase ethanol contributes to air pollution through oxidation to acetaldehyde, with subsequent production of ozone, and in high $\mathrm{NO}_{x}$ regions production of peroxyacetyl nitrate (PAN). However, combustion of ethanol can also lower emissions of acetaldehyde precursors such as alkenes, suggesting that the potential impact of ethanol combustion is complex. The large increase in the concentration of ethanol in both the gas and condensed phases indicates that existing sinks are not sufficient to remove the excess alcohol being added to the atmosphere from biofuel use. This suggests that the projected growth of ethanol as a biofuel will result in considerable increases in atmospheric concentrations within the next few years with direct ramifications on a host of fundamentally important atmospheric processes.

npj Climate and Atmospheric Science (2019)2:3 ; https://doi.org/10.1038/s41612-018-0059-z

\section{INTRODUCTION}

The use of ethanol as a biofuel is increasing because it is a renewable transportation fuel with a potentially lower carbon dioxide atmospheric impact compared to fossil fuels. Ethanol is not completely combusted in automobile engines and hence adds to the oxygenated volatile organic compound atmospheric burden, where it can contribute to smog and ozone formation. Multiple ethanol sources and sinks have been identified, but remain poorly quantified. Because ethanol is highly water soluble, removal by rainwater and dissolution into surface waters are sinks for atmospheric ethanol. Here we show that these and other sinks for atmospheric ethanol are not sufficient to remove the excess ethanol being added to the atmosphere due to increased biofuel use, which has resulted in rapid and dramatic increases of ethanol in both air and rainwater over the last 8 years.

The use of ethanol as a transportation fuel in the USA has doubled in the last decade (https://www.eia.gov/, 2017). Combustion of $10 \%$ ethanol in gasoline (E10) emits less carbon monoxide ${ }^{1,2}$ but usually more $\mathrm{NO}_{x}{ }^{3}$ than pure gasoline per $\mathrm{km}$. However, some fuel ethanol is emitted to the atmosphere through evaporation ${ }^{4}$ and from tailpipes as uncombusted ethanol by vehicle exhaust. ${ }^{5,6}$ The production of ethanol through distillation also releases ethanol to the atmosphere. ${ }^{7}$ Ethanol reacts with hydroxyl radical to produce acetaldehyde, which is the primary sink for atmospheric ethanol, thereby potentially contributing to ozone and smog formation including peroxyacetyl nitrate (PAN). ${ }^{8}$ However, combustion of ethanol emits lower amounts of acetaldehyde precursors including aromatics and alkenes compared to gasoline, ${ }^{5}$ making prediction of impacts less certain.
Because of its high water solubility, atmospheric ethanol can be removed by dissolution into rainwater ${ }^{9}$ and surface waters. ${ }^{10,11}$

Although biogenic sources are thought to be the main contributor to ethanol in the global atmosphere, ${ }^{12,13}$ de Gouw et al. ${ }^{14}$ suggested that more than half the ethanol emitted to the atmosphere in the NE US in 2002 and 2004 and in Los Angeles, CA, USA, in 2010 was direct emissions from anthropogenic activities. Higher gas phase ethanol concentrations in Los Angeles in 2010 compared with the NE US in the earlier years were attributed to greater use of ethanol biofuel. Salvo and Geiger $^{2}$ used a unique opportunity in São Paulo Brazil when the price of gasoline dropped relative to ethanol to show that ozone concentrations decreased by $20 \%$ when more gasoline $(75 \%$ vs. $14 \%)$ was used during the time of their study (2009-2011). ${ }^{2}$ Even though in the UK gasoline contains only $5 \%$ ethanol, ethanol is the most abundant volatile organic compound (VOC) in London air. ${ }^{15} \mathrm{~A}$ modeling study of the air quality impacts of the increased use of ethanol under the USA Energy Independence and Security $\mathrm{Act}^{16}$ predicts a doubling of atmospheric ethanol between 2007 and 2022.

This study presents a unique 8-year data set of rainwater ethanol concentrations collected on an event basis from 2010 through 2017 collected in Wilmington, NC, USA, with comparison to $\mathrm{km}$ driven in North Carolina during that time. Gas phase atmospheric ethanol concentrations are also presented for diurnal experiments in July of 2011 and 2016 under similar meteorological conditions. It is imperative to understand processes that affect the concentration of ethanol in the atmosphere in order to make appropriate decisions about the future use of ethanol as a biofuel.

\footnotetext{
${ }^{1}$ Department of Chemistry and Biochemistry, University of North Carolina Wilmington, 601 S. College Road, Wilmington, NC 28403-3952, USA and ${ }^{2}$ Department of Physical and Environmental Science, Texas A \& M University_Corpus Christi, 6300 Ocean Drive, Corpus Christi, TX 78412, USA

Correspondence: Joan D. Willey (willeyj@uncw.edu)
}

Received: 7 September 2018 Accepted: 5 December 2018

Published online: 14 January 2019 


\section{RESULTS}

\section{Rainwater concentrations}

The concentration of ethanol in rainwater was measured in event rain samples collected on the University of North Carolina Wilmington campus during the summer of 2010 and continuously since January of 2011. The annual volume-weighted average concentrations increased slightly from 2010 through 2013, then more extensively from 2013 through 2015, and then dramatically in 2016 (Fig. 1). The increase from 2010 to 2017 is approximately fourfold. The increasing trend (Mann-Kendall Trend Analysis) is significant (Fig. 1, $p=0.043$ for eight volume-weighted averages (VWA), $p<0.0001$ for raw data, $n=424$ rain samples). This trend is not dependent on the high 2016 concentration because when this point is excluded, the Mann-Kendall trend for $n=7$ is significant at $p=0.004$, and the correlation coefficient increased from $R=$ $0.8678(p<0.01)$ to $R=0.9291$ with $p<0.001$. The 2016 point is not an outlier (Grubbs test, $p=0.4$ ); therefore, it has been included in all analyses. This increase cannot be explained by changes in temperature because the annual average temperature $\left(18.4 \pm 0.8^{\circ} \mathrm{C}\right)$ in Wilmington did not vary in a consistent pattern over this time period. Annual rainfall amounts in Wilmington were greater in 2015 and 2016 due to excessive rain from tropical systems in the summer and autumn, and excessive rain from the 2015-2016 El Niño winter events (https://www.weather.gov/ilm/, 2017). Extensive flooding occurred in Wilmington and surrounding areas in September and October of 2016 due to the historic amounts of tropical rain received (https://www.weather.gov/ilm/, 2017). Four different tropical storms plus Hurricane Matthew delivered significant tropical rain in September and October of 2016, with subsequent flooding. Excessive dilution by the large volume of rain received $(11.2 \mathrm{~cm}$ from Hurricane Matthew) was not observed during Hurricane Matthew because this rain had a relatively high concentration of $937 \mathrm{nM}$. Flooding during 2016 likely contributed to the high concentration observed because episodically submerged plants emit large quantities of ethanol to air. ${ }^{17-19}$ The highest gas phase ethanol concentration observed in the current study was collected above submerged vegetation during flooding ( $>15$ ppbv vs. background concentration of ethanol on a nearby undeveloped island (Masonboro Island) with marine air mass back trajectory of $0.12 \pm 0.03$ ppbv $^{11}$ ).

Much of the increase observed in Fig. 1 may be related to increased use of biofuel ethanol as indicated by the number of $\mathrm{km}$ driven by vehicles per year in North Carolina, USA where the field site is located ${ }^{20}$ (Fig. 2), because of evaporation ${ }^{4}$ and also the release of uncombusted ethanol in vehicle exhaust. ${ }^{5}$ The amount of ethanol in gasoline in the USA has also increased from $8 \%$ in

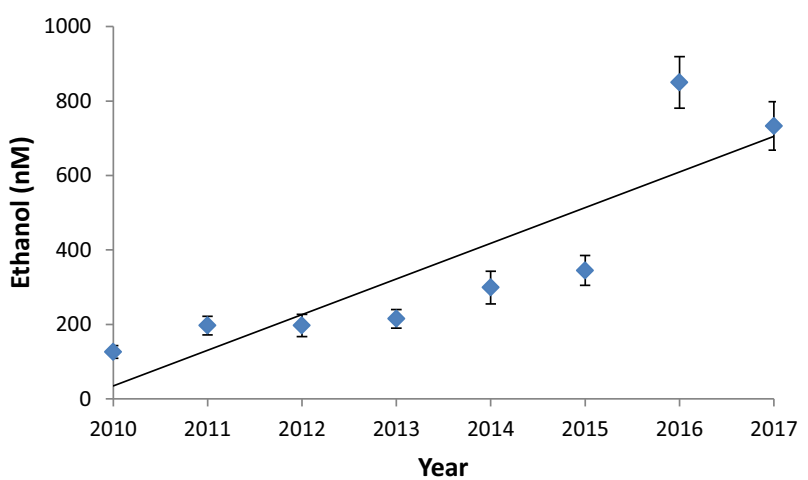

Fig. 1 Volume-weighted annual average rainwater concentration and standard deviations for ethanol in $\mathrm{nM}$ vs. year for rainwater collected in Wilmington, NC, USA. The year 2010 contains summer data only $(n=11)$. The Mann-Kendall Trend Analysis for these data is significant at $p=0.043$; the regression line shown has $R=0.8678$ and $p<0.01$ for $n=8$
2009 to $10 \%$ in 2011 and beyond (https://www.eia.gov/, 2017). The Wilmington NC population $(117,500$ in 2016) increased by $10 \%$ from 2010 to 2016 which would also contribute to higher atmospheric ethanol concentrations in this region. However, these small changes cannot explain the magnitude or timing of the increase observed. Furthermore, compound-specific-stable carbon isotope analysis revealed that on average $59 \%$ of ethanol in rainwater $(n=4$, [ethanol] $>1 \mu \mathrm{M})$ collected in Wilmington, NC, USA during 2016-2017 was sourced from biofuel ethanol, ${ }^{21}$ which suggests that anthropogenic activities are dominating the biogeochemical cycling of ethanol in the southeastern USA. Even though North Carolina is not a large ethanol-producing or -consuming state, the 3-day atmospheric residence time for ethanol $^{12,22}$ allows for transport of ethanol from thousands of $\mathrm{km}$ away (Fig. 3) so the North Carolina atmosphere is affected by distant activities.

\section{Atmospheric concentrations}

Two extensive gas phase experiments were conducted to complement rainwater measurements in the current study. Previous research at this location revealed high variations in gas phase ethanol concentrations over time periods of hours as a function of time of day; ${ }^{23}$ therefore, measurements must be taken over at least a diurnal cycle to compare changes in concentrations over time. Two gas phase studies were conducted 5 years apart, both on the UNCW campus, one on July 5, 2011 and one on July 25,2016 . The air mass back trajectories for these two dates were very similar so air mass back trajectory was not a factor in the observed difference between these two experiments (Fig. 3). The results of these two gas phase studies, each of which included multiple readings over $24 \mathrm{~h}$, suggest gas phase ethanol has increased over the last 5 years, perhaps by as much as fivefold (Table 1), similar to the increase observed in rainwater when comparing 2011 with 2016 concentrations (3.3 fold, $t$ test, $p<$ $0.0001)$. This increase in atmospheric ethanol occurred over a similar time period (2011-2014, the most recent year for which data are available) when highway vehicle emissions of VOCs in North Carolina decreased by $25 \%$, indicating that ethanol is becoming a larger proportion of total VOCs in this area. ${ }^{24}$ De Gouw et al. ${ }^{14}$ found a much greater increase $(30 \times)$ in atmospheric ethanol when comparing atmospheric ethanol concentration in the NE US in 2002 and 2004 with that in Los Angeles in 2010 which they also attribute to greater ethanol biofuel use; the magnitude of the increase observed however probably reflects in part the two different locations used in the study as well as the temporal variability.

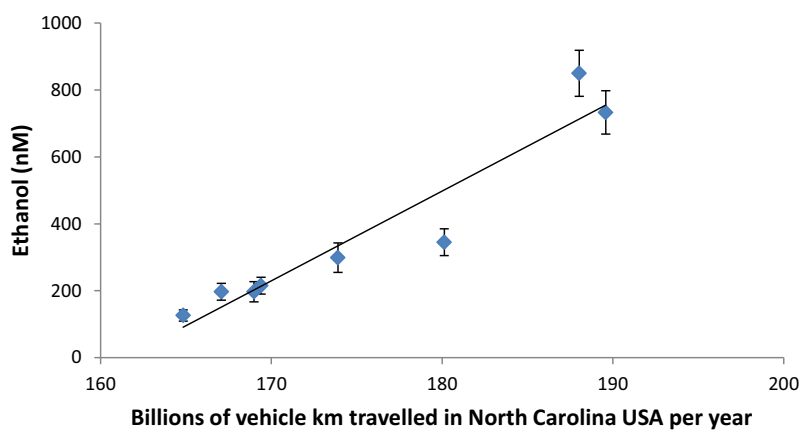

Fig. 2 Volume-weighted annual average rainwater concentration of ethanol in $\mathrm{nM}$ with standard deviations for rainwater collected in Wilmington, NC, USA between 2010 and 2017 vs. billions of km driven by vehicles in North Carolina, USA, per year over the same time frame. For the regression line, $R=0.9517, n=8$ and $p<0.001$ 


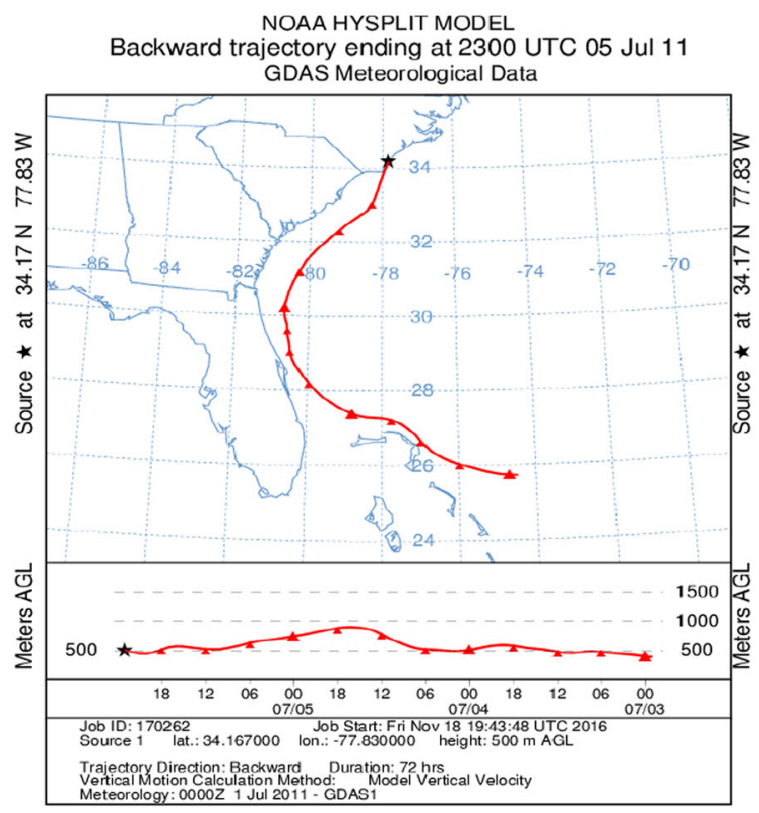

NOAA HYSPLIT MODEL

Backward trajectory ending at 2300 UTC 25 Jul 16 GDAS Meteorological Data

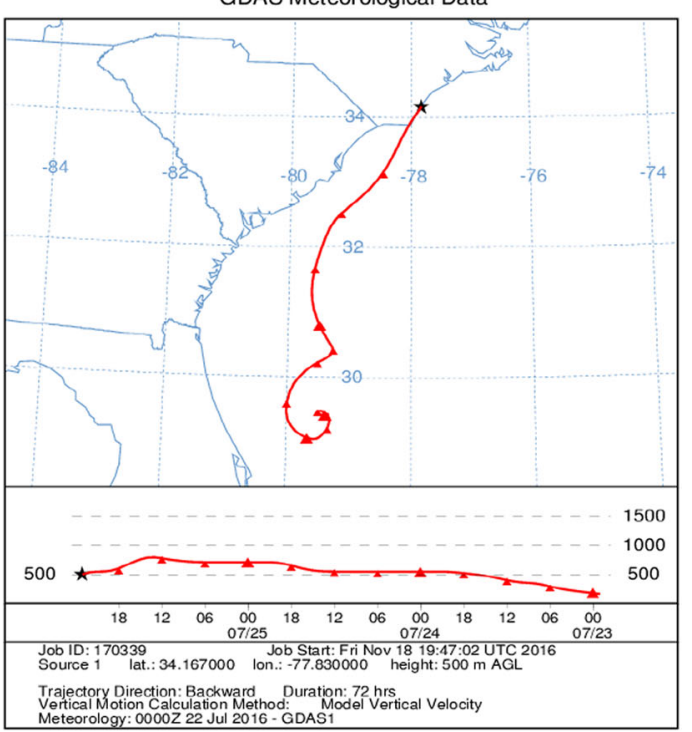

Fig. 3 Air mass back trajectory analyses (https://ready.arl.noaa.gov/hypub-bin/trajtype.pl?runtype=archive, 2017) at $500 \mathrm{~m}$ for the $72 \mathrm{~h}$ prior to the diurnal experiments shown in Table 1

Table 1. Average measured concentrations and standard deviations of ethanol in air over $24 \mathrm{~h}$ for the dates shown compared with concentrations calculated from rainwater event sample concentrations using Henry's Law during the month of July in each year in ppbv

\begin{tabular}{llll}
\hline & $n$ & Average, ppbv & Method \\
\hline 2011 & 12 & $0.78 \pm 0.33$ & Measured \\
July 5 air & 7 & $1.17 \pm 0.81$ & Calculated \\
July rain & & & \\
2016 & 22 & $3.91 \pm 2.58$ & Measured \\
July 25 air & 6 & $5.10 \pm 0.57$ & Calculated \\
July rain & & & \\
\hline$n$ number of samples. Measured and calculated air concentrations are the \\
same for each year $(t$ test, $p>0.1) ;$ however, they are significantly different \\
between 2011 and $2016(t$ test, $p<0.001)$.
\end{tabular}

Air-rainwater interaction

The partitioning of ethanol between the gas and aqueous phases can be described using Henry's Law for a system at equilibrium as follows:

$$
[\mathrm{EtOH}(\mathrm{aq})]=K_{\mathrm{H}} P_{\mathrm{EtOH}} \text {, }
$$

where brackets indicate aqueous concentration of ethanol in $M$, $K_{\mathrm{H}}$ is the Henry's Law constant for ethanol at the relevant temperature in $\mathrm{Matm}^{-1}$, and $P_{\mathrm{EtOH}}$ is the partial pressure of ethanol (atm) in the gas phase in contact with the aqueous phase. In this application, the aqueous phase is rainwater, and the gas phase is air. Using the measured ethanol concentration in rainwater, and the known Henry's Law constant for the temperature of the rain event, ${ }^{11,25}$ the equilibrium atmospheric partial pressure of ethanol can be calculated.

The first diurnal experiment was conducted on July 5, 2011, with 12 air samples collected over $24 \mathrm{~h}$. Even though there was substantial diurnal variation driven by photochemical production of ethanol, ${ }^{23}$ the 2011 gas phase concentrations were much lower than the concentrations observed during a similar diurnal study on July 25, 2016 with 22 samples collected over $24 \mathrm{~h}$ ( $t$ test, $p<$ 0.001 ). Rainwater concentrations from individual events during the month of July in each of the two study years were used along with the appropriate Henry's Law Constant for the ambient temperature to calculate air concentrations in equilibrium with these rainwater concentrations. The average calculated air concentrations were the same as the measured air concentrations in each year (Table 1, $t$ test, $p>0.1$ ), which indicates rainwater is in equilibrium with gas phase ethanol at the collection location at the times of these experiments. The remarkable agreement between the predicted and measured gas phase concentrations are the first field data indicating that rainwater ethanol concentrations are in equilibrium with the gas phase at the time and location where the rain falls, which was assumed by earlier atmospheric models of ethanol cycling. ${ }^{12,13}$ Therefore, atmospheric and rainwater ethanol concentrations are coupled in accordance with Henry's Law, and hence both are likely to increase in the near future.

\section{DISCUSSION}

Air and rainwater ethanol concentrations have increased approximately fourfold between 2010 and 2017 in response to increasing production and use of ethanol as a biofuel, and are likely to increase dramatically in the near future as ethanol biofuel use increases. The observed increase is much greater than the doubling predicted by the year $2022 .{ }^{16}$ The atmospheric impacts of this increased ethanol, and the increase in acetaldehyde that accompanies $i^{5,8,26,27}$ are complex, and depend upon many factors including ambient ${ }^{28}$ and exhaust ${ }^{27}$ temperatures, and the relative concentrations of VOCs and $\mathrm{NO}_{x}{ }^{27}$ Ozone concentrations are most often predicted to increase; however in certain situations ozone can decrease. ${ }^{16,27}$ Both field observation and model predictions indicate that under high $\mathrm{NO}_{x}$ conditions, additional ethanol can contribute to substantial increases in the smog component PAN. ${ }^{8,28,29}$ The use of ethanol as a biofuel therefore does not necessarily improve air quality relative to gasoline as a fuel.

Rainwater ethanol concentrations are close to or at equilibrium with local atmospheric gas phase concentrations suggesting that rainwater is a predictable sink for gas phase ethanol. The absolute removal of ethanol by rainwater will increase as ethanol concentrations increase in air; however, the relative magnitude 
of this change compared with other sources and sinks is unknown in this dynamic system. It is clear from these data that existing sinks including rainwater are not sufficient to remove ethanol at the rate at which it is being added to the atmosphere. Because of the potential impacts of increasing ethanol on air quality, especially in high traffic urban areas, further study of this complex system is urgently needed.

\section{METHODS}

\section{Rainwater collection}

Rainwater was collected on the University of North Carolina Wilmington campus $\left(34.227^{\circ} \mathrm{N}, 77.858^{\circ} \mathrm{W}\right)$ located $8.5 \mathrm{~km}$ away from the Atlantic Ocean. The collection site at UNCW is a large open area of approximately $0.01 \mathrm{~km}^{2}$ and is made up of a turkey oak, long leaf pine and wire grass community typical of the inland coastal area of southeastern North Carolina. Collection was done on an event basis using an AerochemMetrics (ACM) model 301 automatic sensing wet/dry precipitation collector containing a $4 \mathrm{~L}$ Pyrex glass beaker. All glassware used for rain collection, filtration, storage, and analysis was rinsed with Milli-Q Plus Ultra pure deionized water (resistivity $>18 \mathrm{M \Omega} \mathrm{cm}^{-1}$ ) and then combusted at $450^{\circ} \mathrm{C}$ in a muffle furnace for at least $4 \mathrm{~h}$ to remove organic contaminants. Samples were filtered within minutes of collection under low vacuum through a $0.2-\mu \mathrm{m}$ Gelman Supor polysulfone filters in a glass filtration apparatus.

\section{Condensate collection}

Samples for gas-phase ethanol concentration studies were obtained by collecting the condensate from the outside of test tubes filled with ice. The glass tubes and all glassware used for collection and analysis were cleaned with Milli-Q DI water followed by combustion at $450^{\circ} \mathrm{C}$ for a minimum of $4 \mathrm{~h}$ prior to use. Condensation was collected over $1-2 \mathrm{~h}$ at or close to ground level. Air temperature, relative humidity, and wind speed were measured before and after sample collection using a Kestrel 3000 weather meter. Gas phase ethanol was calculated from condensate concentrations using the equation for a moderately soluble gas. ${ }^{30}$ Condensate was collected at the UNCW rain site and at the Bluthenthal Wildflower Preserve less than $1 \mathrm{~km}$ away. Collections were also done proximal to episodically flooded areas as described in the text.

\section{Air mass back trajectories}

Air mass back trajectory analysis (https://ready.arl.noaa.gov/hypub-bin/ trajtype.pl? runtype $=$ archive, 2017) at $500 \mathrm{~m}$ for $72 \mathrm{~h}$ was used to indicate the origins of air masses. This 72-h time period is close to the reported atmospheric residence times of ethanol of 2.8 days $^{12}$ and 3.6 days. ${ }^{22}$

\section{Ethanol analysis}

Ethanol was determined by three analytical methods during this 8-year study: enzyme oxidation (detection limit $(D L)=10 \mathrm{nM}$ ), solid phase micro extraction (with $\mathrm{DL}=19 \mathrm{nM}$ ), and static headspace GC-MS/MS analysis (DL $=28 \mathrm{nM}$ ). The three methods have been described and compared extensively and produce equivalent results for the types of samples used in this study. ${ }^{31,32}$ Samples for ethanol analysis (condensate and rainwater) were analyzed in triplicate when the sample volume permitted. Samples were analyzed immediately when the enzyme method was used for analysis. Other samples were refrigerated at $4{ }^{\circ} \mathrm{C}$ in glass vials with minimal headspace and preserved with $70 \mu \mathrm{L}$ of $100 \mathrm{mg} / \mathrm{mL} \mathrm{HgCl}$ (Alfa Aesar, $>98 \%$ ) per $40 \mathrm{~mL}$ sample to eliminate biological activity such as microbial degradation or production of ethanol. ${ }^{31}$ The concentration of ethanol in samples preserved in this way with $\mathrm{HgCl}_{2}$ did not significantly change within 158 days of storage. ${ }^{7,31}$

\section{Data analysis}

Rainwater ethanol concentrations are reported as VWA, and volume weighted standard deviations to minimize the influence of small volume rain events on concentrations. ${ }^{33}$ This is equivalent to combining all samples and analyzing one representative sample. One outlier was removed from the Wilmington rainwater data: Event 1384 from January $1,2014,19 \mathrm{~mm}$ of rain with an ethanol concentration of $6020 \mathrm{nM}(p<$ 0.0001 , Grubbs test). Mann-Kendall Trend Analysis was performed on rainwater data using annual VWA and also on raw event concentration data. Climatological data for Wilmington NC were obtained from the annual climate summaries (https://www.weather.gov/ilm/, 2017).

\section{DATA AVAILABILITY}

The datasets generated and/or analyzed during the current study are available from the corresponding author on reasonable request.

\section{ACKNOWLEDGEMENTS}

The authors gratefully acknowledge the Marine and Atmospheric Chemistry Research Laboratory at the University of North Carolina Wilmington for wet deposition sample collection and processing. Funding was provided by National Science Foundation grants AGS 1003078, AGS 1440425, and CHE-1336770.

\section{AUTHOR CONTRIBUTIONS}

All authors researched, collated, wrote and edited this paper.

\section{ADDITIONAL INFORMATION}

Competing interests: The authors declare no competing interests.

Publisher's note: Springer Nature remains neutral with regard to jurisdictional claims in published maps and institutional affiliations.

\section{REFERENCES}

1. Graham, L. A., Belisle, S. L. \& Baas, C. L. Emissions from light duty gasoline vehicles operating on low blend ethanol gasoline and E85. Atmos. Environ. 42, 4498-4516 (2008).

2. Salvo, A. \& Geiger, F. M. Reduction in local ozone levels in urban São Paulo due to a shift from ethanol to gasoline use. Nat. Geosci. 7, 450-458 (2014).

3. U.S. EPA. Biofuels and the Environment: The Second Triennial Report to Congress. U. S. Environmental Protection Agency, Washington, DC, EPA/600/R-18/195, https:// cfpub.epa.gov/si/si_public_record_report.cfm?dirEntryld=341491, (2018).

4. Gentner, D. R., Harley, R. A., Miller, A. M. \& Goldstein, A. H. Diurnal and seasonal variability of gasoline-related volatile organic compound emissions in Riverside, California. Environ. Sci. Technol. 43, 4247-4252 (2009).

5. Poulopoulos, S. G., Samaras, D. P. \& Philippopoulos, C. Regulated and unregulated emissions from an internal combustion engine operating on ethanol-containing fuels. Atmos. Environ. 35, 4399-4406 (2001).

6. Colon, M., Pleil, J. D., Hartlage, T. A., Guardani, M. L. \& Martins, M. H. Survey of volatile organic compounds associated with automotive emissions in the urban airshed of Sao Paulo, Brazil. Atmos. Environ. 35, 4017-4031 (2001).

7. Felix, J. D. et al. Removal of atmospheric ethanol by wet deposition. Glob. Biogeochem. Cy 31, 348-356 (2017).

8. Tanner, R. L., Miguel, A. H., Deandrade, J. B., Gaffney, J. S. \& Streit, G. E. Atmospheric chemistry of aldehydes-enhanced peroxyacetyl nitrate formation from ethanol-fueled vehicular emissions. Environ. Sci. Technol. 22, 1026-1034 (1988).

9. Kieber, R. J., Tatum, S., Willey, J. D., Avery, G. B. \& Mead, R. N. Variability of ethanol and acetaldehyde concentrations in rainwater. Atmos. Environ. 84, 172-177 (2014).

10. Avery, G. B. et al. Surface waters as a sink and source of atmospheric gas phase ethanol. Chemosphere 144, 360-365 (2016).

11. Willey, J. D., Powell, J. P., Avery, G. B., Kieber, R. J. \& Mead, R. N. Use of experimentally determined Henry's Law and salting-out constants for ethanol in seawater for determination of the saturation state of ethanol in coastal waters. Chemosphere 182, 426-432 (2017).

12. Naik, V. et al. Observational constraints on the global atmospheric budget of ethanol. Atmos. Chem. Phys. 10, 5361-5370 (2010).

13. Kirstine, W. V. \& Galbally, I. E. The global atmospheric budget of ethanol revisited. Atmos. Chem. Phys. 12, 545-555 (2012).

14. de Gouw, J. A. et al. Increasing atmospheric burden of ethanol in the United States. Geophys. Res. Lett. 39, L15803 (2012).

15. Dunmore, R. E. et al. Atmospheric ethanol in London and the potential impacts of future fuel formulations. Faraday Discuss. 189, 105-120 (2016).

16. Cook, R. et al. Air quality impacts of increased use of ethanol under the United States Energy Independence and Security Act. Atmos. Environ. 45, 7714-7724 (2011).

17. Macdonald, R. C. \& Kimmerer, T. W. Ethanol in the stems of trees. Physiol. Plant. 82, 582-588 (1991). 
18. Rottenberger, S. et al. The effect of flooding on the exchange of the volatile C-2compounds ethanol, acetaldehyde and acetic acid between leaves of Amazonian floodplain tree species and the atmosphere. Biogeosciences 5, 1085-1100 (2008).

19. Copolovici, L. \& Niinemets, U. Flooding induced emissions of volatile signalling compounds in three tree species with differing waterlogging tolerance. Plant Cell Environ. 33, 1582-1594 (2010).

20. USA Office of Highway Policy Information, Traffic Volume Trends, https://www. fhwa.dot.gov/policyinformation/travel_monitoring/tvt.cfm (2018).

21. Felix, J. D. et al. Compound specific carbon isotope composition of ethanol in Brazil and US vehicle emissions and wet deposition. Environ. Sci. Technol. in press (2018).

22. Mellouki, A., Wallington, T. J. \& Chen, J. Atmospheric chemistry of oxygenated volatile organic compounds: impacts on air quality and climate. Chem. Rev. 115 3984-4014 (2015).

23. Kieber, R. J. et al. Diurnal variability of gas phase and surface water ethanol in southeastern North Carolina, USA. Atmos. Environ. 168, 55-61 (2017).

24. USA EPA National Emissions Inventory, https://www.epa.gov/air-emissionsinventories/2014-national-emissions-inventory-nei-data (2017).

25. Warneck, P. A note on the temperature dependence of Henry's Law coefficients for methanol and ethanol. Atmos. Environ. 40, 7146-7151 (2006).

26. Anderson, L. G. Ethanol fuel use in Brazil: air quality impacts. Energy Environ. Sci. 2, 1015-1037 (2009).

27. Hubbard, C. P., Anderson, J. E. \& Wallington, T. J. Ethanol and air quality: influence of fuel ethanol content on emissions and fuel economy of flexible fuel vehicles. Environ. Sci. Technol. 48, 861-867 (2014).

28. Ginnebaugh, D. L., Liang, J. \& Jacobson, M. Z. Examining the temperature dependence of ethanol (E85) versus gasoline emissions on air pollution with a largely-explicit chemical mechanism. Atmos. Environ. 44, 1192-1199 (2010).

29. Jacobson, M. Z. Effects of ethanol (E85) versus gasoline vehicles on cancer and mortality in the United States. Environ. Sci. Technol. 41, 4150-4157 (2007).
30. Snider, J. R. \& Dawson, G. A. Tropospheric light alcohols, carbonyls, and acetonitrile-concentrations in southwestern United-States and Henry Law data. J. Geophys Res-Atmos. 90, 3797-3805 (1985).

31. Kieber, R. J. et al. Determination of ambient ethanol concentrations in aqueous environmental matrixes by two independent analyses. Anal. Chem. 85 6095-6099 (2013).

32. Mead, R. N. et al. A static headspace GC-MS/MS method for the determination of ethanol, iso-butanol and n-butanol at nanomolar concentrations in aqueous environmental samples. Limnol. Oceanogr. Methods. 15, 1007-1014 (2017).

33. Mullaugh, K. M., Kieber, R. J., Willey, J. D. \& Avery, G. B. Long-term temporal variability in hydrogen peroxide concentrations in Wilmington, North Carolina USA rainwater. Environ. Sci. Technol. 45, 9538-9542 (2011).

(i) Open Access This article is licensed under a Creative Commons Attribution 4.0 International License, which permits use, sharing, adaptation, distribution and reproduction in any medium or format, as long as you give appropriate credit to the original author(s) and the source, provide a link to the Creative Commons license, and indicate if changes were made. The images or other third party material in this article are included in the article's Creative Commons license, unless indicated otherwise in a credit line to the material. If material is not included in the article's Creative Commons license and your intended use is not permitted by statutory regulation or exceeds the permitted use, you will need to obtain permission directly from the copyright holder. To view a copy of this license, visit http://creativecommons. org/licenses/by/4.0/.

c The Author(s) 2019 